\title{
PENGARUH CELEBRITY ENDORSER HAMIDAH RACHMAYANTI TERHADAP KEPUTUSAN PEMBELIAN PRODUK ONLINE SHOP MAYOUTFIT DI KOTA BANDUNG
}

\author{
R. Ratika Zahra ${ }^{1}$, Nofha Rina ${ }^{2}$. \\ Program Studi Ilmu Komunikasi Fakultas Komunikasi dan Bisnis, Universitas Telkom \\ zahratikaaa@gmail.com ${ }^{1}$, nofharina80@gmail.com ${ }^{2}$
}

\begin{abstract}
Utilization of internet among modern society today is the use of social media. Of the many social media that are present to be consumed by modern society and one of them is Instagram useful benefits for the delivery of new information including one that is also used dalah things do business. The emergence of the phenomenon of online shopping in social media Instagram for the vigorous business conduct marketing using supporting figures or celebrities endorser as a supporter to market their products. Seeing this phenomenon, it is necessary to do a research that. Hamidah Rachmayanti is a celebrity endorser used by Online Shop Mayoutfit has several purposes in this research is to determine the effect of Visibility, Credibility, Attractiveness and Celebrity Endorser Effectiveness to the Decision Purchase Online Shop Mayoutfit products. This research uses quantitative method with questionnaire distribution and using multiple linear regression. This study concludes that the influence of Celebrity Endorser on @ hamidahrachmayanti account of $52.1 \%$ can be explained by variables consisting of Visibility, Credibility, Attractiveness, and Power. This means that these four variables give the effect of $52.1 \%$ of Purchase Decision. While the rest of $47.9 \%$ is the contribution of other variables that are not examined in this study.
\end{abstract}

Keywords: Celebrity Endorser, Purchase Decision, Instagram.

\section{PENDAHULUAN}

Perkembangan pengguna internet di Indonesia terutama dalam penggunaan media sosial, memberikan dampak pada perubahan pola perilaku konsumtif masyarakat Indonesianya itu sendiri terhadap internet. Pola perilaku masyarakat cenderung menjadi lebih memilih hal yang praktis dan lebih cenderung memilih untuk mengkonsumsi informasi melalui internet dan media sosial dibandingkan dengan pencarian informasi melalui konvensional seperti pencarian informasi di koran atau majalah. Dengan semakin bertambahnya angka penggunaan media sosial yang telah dilansir pada Asosiasi Penyelenggara Jasa Internet Indonesia (APJII) dan hasil surveinya pertahun 2016, mengatakan bahwa tiga media sosial yang paling banyak diakses oleh masyarakat Indonesia salah satunya yaitu Instagram.

Pemanfaatan internet dikalangan masyarakat modern saat ini adalah penggunaan media sosial. Dari banyaknya media sosial yang hadir untuk dapat dikonsumsi oleh masyarakat modern ini dan salah satunya yaitu Instagram menimbulkan manfaat yang berguna untuk penyampaian informasi baru termasuk salah satunya yang juga dimanfaatkan dalah hal berbisnis.

Semakin berkembang komunikasi pemasaran yang dilakukan melalui media internet, hal tersebut menyebabkan timbulnya kompetisi antar perusahaan ataupun bisnis perorangan yang semakin 
ketat, dengan tujuan menggunakan media sosial agar dapat menjalin komunikasi antar satu orang kepada khalayak yang terpisahkan oleh jarak, menjadi pilihan banyak orang ataupun perusahaan untuk memanfaatkan hal tersebut. Pada saat ini media sosial menjadi sebuah ladang bisnis untuk meraup keuntungan sebesar besarnya dalam menjalankan bisnisnya dengan menjadi salah satu saluran pemasaran dan muncul istilah Online Shop atau toko virtual yang menjual produknya secara Online.

- Instagram merupakan suatu aplikasi yang dapat membagikan foto yang memungkinkan pengguna Instagram tersebut dapat mengunggah foto, video, atau hal yang menarik dengan ditambah fitur filter efek digital dan baru akhir tahun 2016 Instagram menambahkan fitur Live yang membuat para pengguna dapat membagikan ceritanya dan di lihat oleh para pengikutnya atau yang disebut followersnya secara langsung. Media sosial Instagram kini telah menjadi pilihan alternatif dalam dunia perindustrian yang memasarkan produk atau barang jasa menggunakan Instagram.

Dalam melakukan pemasaran di era sekarang, banyaknya perusahaan atau bisnis perorangan dituntut untuk menlakukan berbagai macam stategi dengan tujuan untuk menarik para calon konsumen untuk menimbulkan rasa ketertarikan pada produk yang dipasarkan. Perusahaan dituntut untuk lebih dapat mengkomunikasikan pesan dengan baik dan menarik, agar hal tersebut menimbulkan kepekaan konsumen untuk melihat produk yang dipasarkan. Strategi pemasaran yang dilakukan oleh perusahaan akan menjadi hal terpenting dan berpengaruh pada penjualan khususnya dalam hal promosi produk. Menurut Shimp (2003:457) mengatakan bahwa kaum selebriti khususnya Celebrity Endorser yang hanya berfokus untuk melakukan perkerjaan dengan menerima endorsement merupakan hal utama dalam sebuah pemasaran periklanan, banyaknya konsumen dengan mudah mengidentifikasi diri dengan para selebriti tersebut, sering kali dengan memandang mereka sebagai pahlawan atas prestasi, kepribadian, dan daya tarik fisik mereka. Karakteristik sumber pesan merupakan aspek yang harus diperhatikan dalam proses komunikasi karena efek pesan yang diterima komunikan dapat di pengaruhi oleh kredibilitas komunikator, aspek-aspek kredibilitas komunikator bisa dikenal VISCAP yang terdiri dari Visibility, Credibility, attractivness, dan Power.

Para pemasar atau pemasang iklan, akan tumbuh rasa bangga ketika mereka dapat menggunakan kaum selebriti didalam kegiatan pemasarannya tersebut, karena atribut popular yang dimiliki oleh selebriti tersebut termasuk kecantikan, keberanian, bakat, jiwa olahraga, keanggunan, kekuasaan dan daya tarik seringkali merupakan pemikat yang diinginkan untuk merek-merek yang mereka dukung. Tanpa memperhatikan mekanisma khusus cara kaum selebriti meningkatkan nilai sebuah merek, pada kenyataannya mereka layak menerima bayaran yang dibayar oleh para pemasang iklan untuk jasa mereka. Penyampaian pesan melalui iklan kepada calon konsumen harus diperhatikan, dengan itu agar suatu iklan dapat terkemas dengan menarik maka diperlukan kreativitas dalam pembuatan suatu iklan dengan suatu strategi yang kreatif. Salah satu cara membuat sebuah iklan menjadi kreatif dengan menggunakan seorang sosok pendukung yang memiliki kemampuan dalam mempersuasi perhatian orang banyak, dalam hal itu sosok pendukung yang sekarang 
banyak digunakan oleh para pembisnis maupun perusahaan yaitu disebut dengan Celebrity Endorser.

\section{KAJIAN PUSTAKA}

\section{Komunikasi Pemasaran}

Komunikasi adalah proses di mana suatu pemikiran dan pemahaman disampaikan kepada antar individu, atau antara organisasi dengan individu, sedangkan Pemasaran merupakan sekumpulan kegiatan di mana suatu perusahaan dan organisasi lainnya memberikan dan menyerahkan nilai - nilai pertukaran antara mereka dengan pelanggannya. Jika digabungkan, pemahaman mengenai komunikasi pemasaran yaitu merepresentasikan gabungan semua unsur dalam bauran pemasaran merek, yang memfasilitasi terjadinya pertukaran dengan menciptakan suatu arti yang akan disebarluaskan kepada pelanggannya (Shimp, 2003:4). Salah satu ciri dari komunikasi pemasaran, Menurut Shimp dalam bukunya (2003: 22), ciri utama komunikasi pemasaran adalah penggunaan semua sumber hubungan, kontak merek atau perusahaan sebagai jalur penyampai pesan yang potensial yang ditujukan untuk menentukan metode yang paling tepat dan efektif dalam mengembangkan program komunikasi yang persuasif. Ketika dalam menggunakan komunikasi yang efektif dalam melakukan sebuah pemasaran, dan dengan ditambahkannya suatu hal yang kreatif dapat memberikan dampak terhadap penjualan produk atau produk yang sedang dipasarkan.

Menurut Hermawan (2012:54) komunikasi pemasaran akan berdampak pada persepsi yang positif berupa kepercayaan terhadap merek yang akan disampaikan bergantung terhadap proses pelaksanaan yang baik, begitu juga sebaliknya kepercayaan merek akan memperlancar komunikasi pemasaran. Menurut Morissan (2007:10),termasuk dalam komunikasi pemasaran adalah aktivitas pemasaran yang berusaha menciptakan kesadaran atau pengetahuan mengenai produk dengan berbagai atributnya, menginformasikan kelebihan produk, menciptakan citra produk, atau menciptakan sikap positif, preferensi, dan keinginan membeli produk bersangkutan. Tujuan komunikasi mengacu pada apa yang ingin dicapai perusahaan atau organisasi dengan program promosi yang dilakukan.

Berdasarkan definisi diatas dapat disimpulkan bahwa komunikasi pemasaran merupakan suatu cara komunikasi yang ditujukan untuk membantu suatu perusahaan dalam memasarkan produknya. Kegiatan komunikasi pemasaran bertujuan sebagai penyampaian pesan kepada konsumen atau masyarakat secara umum dengan tujuan untuk meningkatkan penjualan produk perusahaan melalui penggunaan berbagai saluran media.

\section{Celebrity Endorser}

Menurut Shimp (2003: 460) selebriti adalah tokoh (aktor, penghibur atau atlet) yang dikenal masyarakat karena prestasinya didalam bidang- bidang yang berbeda dari golongan yang didukung. Para selebriti menerima bayaran untuk jasa dukungan sebagai juru bicara produk.

Celebrity Endorser memiliki beberapa indikator, indikator Celebrity Endorser dalam penelitian ini mengacu pada teori yang di kemukakan oleh (Percy \& Rossiter, 1987) dalam buku Kertamukti (2015:70) bahwa sebuah Celebrity Endorser dapat diukur dari karakteristik endorser dalam komunikasi yakni VisCAP model (Visibility, Credibility, Attraction, Power). 
[JURNAL LONTAR VOL. 6 NO 1 JANUARI-JUNI 2018, 43-57]

VisCap Model digunakan untuk mengevaluasi endroser yang potensial berdasarkan persepsi khalayak terhadap endorser tersebut.

1) Visibility

Menurut Percy \& Rossiter (1987; dalam Elina:2017) mengukapkan bahwa Visibility memiliki dimensi seberapa jauh popularitas seorang selebriti. Apabila dihubungkan dalam popularitas, maka dapat ditentukan dengan seberapa banyak penggemar yang dimiliki oleh seorang Celebrity Endorser (Popularity) tersebut dan bagaimana tingkat keseringan tampilnya didepan khalayak (Appearances).

2) Credibility

Dapat dipercaya dan keahlian seorang selebriti secara bersama - sama disebut kredibilitas merupakan alasan utama untuk memilih selebriti sebagai pendukung periklanan, seseorang yang dapat dipercaya dan dianggap memiliki wawasan tentang isu tertentu, seperti kehandalan merek akan menjadi orang yang paling mampu meyakinkan orang lain untuk mengambil dan memutuskan suatu tindakan (Shimp, 2003:264). Credibility terdiri dari atribut sebagai berikut:

a. Expertise

Keahlian adalah kesan yang dibentuk oleh konsumen tentang kemampuan dan pengetahuan selebriti atau model dalam hubunganya dengan produk. Jika konsumen menganggap bahwa selebriti atau model memiliki kecerdasan, pengetahuan dan pemahaman yang baik maka konsumen cenderung untuk menerimanya. Selain faktor kharisma juga berperan dalam menilai seseorang ahli atau bukan.

b. Objectivity

Konsumen akan membentuk persepsi terhadap reputasi selebriti akan mempengaruhi tindakan yang akan dilakukan oleh konsumen, persepsi konsumen akan memutuskan dalam melakukan pembelian produk yang dipasarkan oleh selebriti.

c. Trustworthiness

Trustworthiness, yaitu kemauan selebriti untuk membuat pernyataan yang jujur. Khalayak menganggap iklan yang disampaikan hanya untuk meningkatkan penjualan, untuk itu perlu seseorang selebriti yang dipersepsikan khalayak jujur dalam memberikan pendapatnya.

3) Attraction

Penerimaan pesan tergantung pada daya tarik endroser. Endroser akan berhasil merubah opini dan perilaku konsumen melalui mekanisme daya tarik. Menurut Shimp (2003:467) menjelaskan bahwa pendukung secara fisik yang menarik akan menghasilkan evaluasi iklan dan produk yang lebih menyenangkan daripada iklan yang menggunakan komunikator yang kurang menarik. Tetapi, bukti empiris menunjukan bahwa pendukung yang menarik lebih efektif jika citra pendukung sesuai dengan sifat produk yang didukung. Daya Tarik endroser memiliki atribut sebagai berikut:

a. Physical Likeability adalah persepsi khalayak berkenan dengan penampilan fisik endorser yang dianggap menarik. Likebility berkenaan dengan suatu cara untuk menggunakan seseorang yang menarik agar orang lain mau melakukan apa yang dikatakan orang tersebut. Pada Umumnya khalayak menyukai endorser yang memiliki kesempurnaan fisik seperti cantik, tampan, berbadan ideal, dan lainlain. 
b. Non-Physical Likeability adalah persepsi khalayak berkenaan dengan penampilan non-fisik atau kepribadian endorser. Pada umumnya khalayak menyukai endorser yang terbuka, penuh candaan, dan alami.

c. Similarity adalah persepsi khalayak berkenaan dengan kesamaan yang dimilikinya dengan sang endorser. Baik itu dari faktor usia, hobi, aktivitas yang dijalani, maupun masalah yang dihadapi sebagaimana yang ditampilan pada pemasarannya.

4) Power

Unsur terakhir dalam model VisCap ini menginformasikan bahwa seorang selebriti yang digunakan dalam iklan harus memiliki kekuatan untuk "memerintahkan" target audiens untuk membeli. Power adalah sejauh mana kemampuan selebriti untuk dapat membujuk para konsumen dan mempertimbangkan produk yang sedang diiklankan untuk dikonsumsi (Kertamukti, 2015:70)

\section{Keputusan Pembelian}

Pada tahap keputusan pembelian terdapat tedapat sub-sub keputusan yang dapat mempengaruhi konsumen dalam proses keputusan pembelian. Morissan (2010:111) menjelaskan bahwa keputusan pembelian merupakan tahap selanjutnya setelah adanya niat atau keinginan membeli, namun keputusan pembelian adalah tidak sama dengan pembelian yang sebenarnya. Menurut Nugroho J. Setiadi (2008:413) berpendapat bahwa proses pengambilan keputusan yang rumit sering melibatkan beberapa keputusan. Suatu keputusan melibatkan pilihan di antara dua atau lebih alternative tinfakan. Keputusan selalu mensyaratkan pilihan di antara beberapa perilaku yang berbeda. Schiffman dan Kanuk (2008: 458) dalam Elina (2017) mendefinisikan suatu keputusan sebagai seleksi terhadap dua pilihan alternatif atau lebih. Dengan perkataan lain, pilihan alternatif harus tersedia bagi sesorang ketika mengambil keputusan. Menurut Kotler dan Keller (2013: 192) mengatakan dalam melaksanakan maksud pembelian, konsumen dapat membentuk lima sub keputusan, sebagai berikut :

a. Keputusan Merek

Konsumen harus mengambil keputusan terhadap suatu merek yang akan dipilih dan dibeli. Pada umumnya, setiap merek yang ada pasti memiliki perbedaan tersendiri, dalam hal tersebut pihak pemasar atau suatu perusahaan harus mengetahui bagaimana proses dan tindakan konsumen dalam memilih sebuah merek.

b. Keputusan Penyalur

Setelah konsumen melakukan pemilihan produk atau merek, konsumen harus mengambil keputusan dimana produk tersebut akan dibeli. Dalam hal ini, pemasar baru akan mengetahui bagaiana konsumen memilih penjualan tertentu.

c. Keputusan Kuantitas

Tahap setelah konsumen melakukan keputusan untuk membeli suatu produk atau merek yang sudah dipilih, konsumen dapat menentukan keputusan untuk seberapa banyak produk yang akan dibelinya pada suatu saat. Hal tersebut, pihak pemasar atau perusahaan harus mempersiapkan banyaknya produk sesuai dengan keinginan yang berbeda antara satu pembeli dengan pembeli yang lain.

\section{d. Keputusan Waktu}

Konsumen dapat memutuskan tentang kapan ia harus melakukan pembelian, hal tersebut akan menyangkut dengan ada atau tidak adanya uang yang dimiliki oleh 
konsumen, oleh karena itu perusahaan atau pihak pemasar harus mengetahui faktor apa saja yang dapat memperngaruhi keputusan konsumen dalam melakukan dan menentukan waktu pembelian.

\section{e. Keputusan Metode Pembayaran}

Konsumen harus memutuskan tentang metode atau cara yang akan dilakukan untuk pembayaran produk yang telah dibeli. Keputusan ini akan mempengaruhi tentang penjualan dan jumlah pembelinya. Dalam hal tersebut perusahaan atau pihak pemasar harus mengetahui keinginan konsumen terhadap cara atau metode pembayarannya, dengan itu perusahaan atau pihak pemasar harus mempersiapkan segala metode pembayaran yang dibutuhkan oleh konsumen.

\section{Model AIDA}

Untuk melakukan promosi, perusahaan harus merancang atau mendesain pesanpesan menjadi efektif. Idealnya, pesan harus mendapat perhatian (Attention), mempertahankan minat (Interest), membangkitkan hasrat (Desire), dan meraih tindakan (Action) (kerangka kerja dikenal sebagai model AIDA). Banyak dari yang kita temukan bahwa hanya sedikit pesan yang membawa konsumen dari kesadaran sampai pembelian, tetapi kerangka kerja AIDA menyarankan kualitas pesan baik yang diinginkan (Kotler dan Armstrong, 2008:125).

Model AIDA merupakan proses pengambilan keputusan pembelian yaitu suatu proses psikologis yang dilalui oleh konsumen atau pembeli, prosesnya yang diawali dengan tahap menaruh perhatian (Attention) terhadap barang atau jasa, kemudian jika berkesan dia melangkah ke tahap ketertarikan (Interest) untuk mengetahui lebih jauh tentang keistimewaan produk atau jasa tersebut, jika intensitas ketertarikannya kuat maka berlanjut ke tahap memiliki hasrat atau keinginan (Desire) karena barang atau jasa yang ditawarkan sesuai dengan kebutuhankebutuhannya. Jika hasrat dan keinginannya begitu kuat baik karena dorongan dari dalam atau rangsangan persuasif dari luar maka konsumen atau pembeli tersebut akan mengambil keputusan membeli (Action to buy) barang atau jasa yang di tawarkan. Jadi, tujuan dilakukan promosi adalah untuk menghasilkan respons pembelian.

\section{Instagram}

Mengacu pada penelitian yang telah dilakukan oleh Sabirin (2015) yang mengadopsi pemahaman menurut Enterprise (2012:02) Instagram adalah komunitas yang saling berbagi antara satu anggota dengan anggota yang lainnya dari seluruh dunia. Instagram menyerupai galeri berukuran raksasa dimana setiap orang bisa melihat hasil karya pengguna Intagram yang lain dan menciptakan jaringan pertemanan. Intagram adalah App (aplikasi) yang tersedia untuk iPhone, iPod, dan iPad. Fungsinya untuk memotret dan mengolah foto itu agar terkesan antik (vintage) dan menyebarkannya ke komunitas. Sehingga demikian, peneliti dapat menyimpulkan bahwasanya Instagram merupakan sebuah aplikasi yang digunakan untuk mengambil foto, mengedit foto, memberi efek filter pada foto, hingga membagikan foto tersebut kepada dunia luas khususnya para followers pengguna pada Instagram.

\section{Pembahasan}

Jenis penelitian yang akan digunakan dalam penelitian ini adalah metode penelitian kuantitatif. Menurut Sugiyono (2012:8), penelitian kuantitatif digunakan untuk 
meniliti pada populasi atau sampel tertentu, pengumpulan data menggunakan instrumen penelitian, analisis data bersifat kuantitatif/statistik, dengan tujuan untuk menguji hipotesis yang telah ditetapkan. Skala yang digunakan dalam desain pengukuran penelitian ini adalah skala Likert. Menurut (Sugiyono, 2014:132) Skala Likert digunakan untuk mengukur sikap, pendapat, dan persepsi seseorang atau sekelompok orang tentang fenomena sosial.

Pada penelelitian ini, peneliti menggunakan skala Likert hanya dengan 4 pilihan. Menurut Susanty (2012, dalam Indrawati, 2015) hasil riset Garland (1991) bahwa menghilangkan poin tengah akan mengeliminasi responden untuk memilih skala netral serta dengaan mengeluarkan pilihan netral akan memberikan hasil yang lebih reliabel. Jawaban setiap item instrumen yang menggunakan skala Likert mempunyai gradasi dari sangat positif sampai sangat negatif, yang dapat berupa kata-kata. Objek dalam penelitian ini adalah Celebrity Endorser dan keputusan pembelian pada produk Mayoutfit. Subjek penelitian merupakan tempat variable melekat. Subjek dalam penelitian ini adalah pengikut akun Instagram Mayoutfit (@mayoutfit) yang sekaligus akan dijadikan sebagai sampel dalam penelitian ini.

\section{Uji Validitas}

Menurut Sugiyono

(2014:24) validitas menunjukan derajat ketepatan antara data yang sesungguhnya terjadi pada obyek dengan data yang dapat dikumpulkan oleh peneliti. Uji validitas diambil berdasarkan data yang didapat dari hasil kuesioner, dengan menggunakan korelasi Pearson Product Moment yaitu korelasi antar item dengan skor total dalam satu variabel, dan pengukuran yang diperoleh dengan menggunakan software SPSS 22.0 dengan tingkat signifikansi $(\alpha)=0,05$ karena dinilai cukup mewakili, dan merupakan tingkat signifikansi yang umum digunakan pada penelitian ilmu sosial. Jumlah sampel $(n)=30$ responden, sehingga diperoleh nilai rtabel sebesar 0,361 .

\begin{tabular}{|c|c|c|c|}
\hline $\begin{array}{c}\text { Pernyataan } \\
\text { (X) }\end{array}$ & $\begin{array}{c}\mathbf{r} \\
\text { hitung }\end{array}$ & $\begin{array}{c}\mathbf{r} \\
\text { tabel }\end{array}$ & Keterangan \\
\hline p1 & 0,633 & 0,361 & Valid \\
\hline p2 & 0,579 & 0,361 & Valid \\
\hline p3 & 0,570 & 0,361 & Valid \\
\hline p4 & 0,665 & 0,361 & Valid \\
\hline p5 & 0,745 & 0,361 & Valid \\
\hline p6 & 0,433 & 0,361 & Valid \\
\hline p7 & 0,513 & 0,361 & Valid \\
\hline p8 & 0,580 & 0,361 & Valid \\
\hline p9 & 0,771 & 0,361 & Valid \\
\hline p10 & 0,509 & 0,361 & Valid \\
\hline p11 & 0,505 & 0,361 & Valid \\
\hline p12 & 0,392 & 0,361 & Valid \\
\hline p13 & 0,623 & 0,361 & Valid \\
\hline p14 & 0,440 & 0,361 & Valid \\
\hline p15 & 0,631 & 0,361 & Valid \\
\hline p16 & 0,525 & 0,361 & Valid \\
\hline p17 & 0,686 & 0,361 & Valid \\
\hline Pernyataan & $\mathbf{r}$ & $\mathbf{r}$ & Keterangan \\
\hline (Y) & hitung & table & \\
\hline p18 & 0,531 & 0,361 & Valid \\
\hline p19 & 0,585 & 0,361 & Valid \\
\hline p20 & 0,569 & 0,361 & Valid \\
\hline p21 & 0,749 & 0,361 & Valid \\
\hline p22 & 0,382 & 0,361 & Valid \\
\hline p23 & 0,552 & 0,361 & Valid \\
\hline p24 & 0,478 & 0,361 & Valid \\
\hline p25 & 0,523 & 0,361 & Valid \\
\hline & & & \\
\hline
\end{tabular}


[JURNAL LONTAR VOL. 6 NO 1 JANUARI-JUNI 2018, 43-57]

\section{Uji Reliabilitas}

Menurut Indrawati (2015:155) reliabilitas adalah menyangkut tingkat keterpercayaan, keterandalan, konsistensi, atau kestabilan hasil suatu pengukuran. Menurut Riduwan (2010:125) uji reliabilitas instrumen penelitian menggunakan rumus Cronbach's Alpha. Cronbach's Alpha adalah rumus matematis yang digunakan untuk menguji tingkat reliabilitas ukuran, dimana suatu instrumen dapat dikatakan handal (reliabel) bila memiliki koefisien keandalan atau alpha sebesar 0,6 atau lebih.

Menurut Sugiyono (2012:220), Instrumen dinyatakan reliabel bila koefisien reliabilitas minimal 0,6. Untuk mempermudah perhitungan uji validitas dan uji realibilitas, maka penulis menggunakan program Microsoft Excel dan SPSS Statistics (Statistical Program of Social Science) 20 version for windows. Berikut adalah hasil uji reliabilitas dari penelitian ini terdapat pada tabel berikut:

Uji Reliabilitas Variable $\mathbf{X}$ Reliability

Statistics

\begin{tabular}{|r|r|}
\hline $\begin{array}{c}\text { Cronbach } \\
\text { 's Alpha }\end{array}$ & $\begin{array}{c}\mathrm{N} \text { of } \\
\text { Items }\end{array}$ \\
\hline, 745 & 17 \\
\hline
\end{tabular}

Sumber : Olahan Penulis Menggunakan SPSS 22.0

Berdasarkan hasil uji reliabilitas pada Celebrity Endorser didapatkan nilai $\alpha$ sebesar 0,745. Hasil tersebut dinyatakan reliabel karena $\alpha>0,6$.

\section{Uji Reliabilitas Variable Y Reliability Statistics

\begin{tabular}{|c|c|}
\hline $\begin{array}{c}\text { Cronbach } \\
\text { 's Alpha }\end{array}$ & $\begin{array}{c}\mathrm{N} \text { of } \\
\text { Items }\end{array}$ \\
\hline
\end{tabular}

\begin{tabular}{|l|l|}
\hline, 700 & 9 \\
\hline
\end{tabular}

Sumber : Olahan Penulis Menggunakan SPSS 22.0

Berdasarkan hasil uji reliabilitas pada Keputusan Pembelian didapatkan nilai $\alpha$ sebesar 0,700 . Hasil tersebut dinyatakan reliabel karena $\alpha>0,6$.

\section{Analisis Deskriptif}

Analisis deskriptif yang dilakukan dalam penelitian ini menggunakan garis kontinum yang menunjukan hasil sebagai berikut :

\begin{tabular}{|l|l|}
\hline Visibility & Sangat Baik \\
\hline Credibility & Baik \\
\hline Attraction & Baik \\
\hline Power & Baik \\
\hline $\begin{array}{l}\text { Keputusan } \\
\text { Pembelian }\end{array}$ & Baik \\
\hline
\end{tabular}

\section{Uji Normalitas}

Uji normalitas dilakukan untuk mengetahui apakah data yang diambil berasal dari populasi yang berdistribusi normal. Model regresi yang baik adalah berdistribusi normal atau mendekati normal. Jika data tidak mengikuti pola sebaran distribusi normal, maka akan diperoleh taksiran yang bias. Pengujian normalitas dilakukan melalui tes Kolmogorov-Smirnov koreksi Lilliefors. Dengan bantuan software SPSS 23 diperoleh hasil sebagai berikut :

Tabel 4.6

Uji Normalitas

One-Sample Kolmogorov-Smirnov Test

\begin{tabular}{|ll|r|}
\hline & & \multicolumn{2}{|c|}{$\begin{array}{c}\text { Unstandardized } \\
\text { Residual }\end{array}$} \\
\hline $\mathrm{N}$ & & 100 \\
Normal & Mean & .0014790
\end{tabular}




\begin{tabular}{|c|c|c|}
\hline $\begin{array}{l}\text { Parameters } \\
, \mathrm{b}\end{array}$ & $\begin{array}{l}\text { Std. } \\
\text { Deviati }\end{array}$ & .54004780 \\
\hline Most & $\begin{array}{l}\text { on } \\
\text { Absolu }\end{array}$ & \\
\hline Extreme & te & .068 \\
\hline Differences & $\begin{array}{l}\text { Positiv } \\
\mathrm{e}\end{array}$ & .062 \\
\hline & $\begin{array}{l}\text { Negati } \\
\text { ve }\end{array}$ & -.068 \\
\hline \multirow{2}{*}{\multicolumn{2}{|c|}{$\begin{array}{l}\text { Test Statistic } \\
\text { Asymp. Sig. (2- } \\
\text { tailed) }\end{array}$}} & .068 \\
\hline & & $.200^{\mathrm{c}, \mathrm{d}}$ \\
\hline
\end{tabular}

a. Test distribution is Normal.

b. Calculated from data.

c. Lilliefors Significance Correction.

$\mathrm{d}$. This is a lower bound of the true significance.

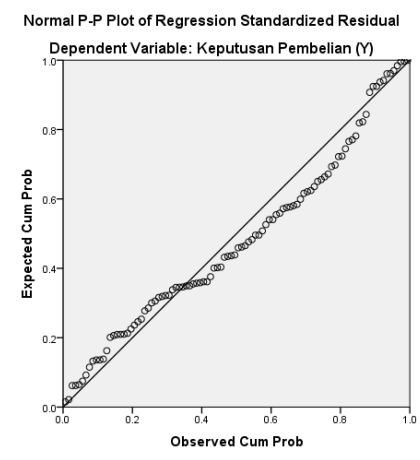

Analisis kenormalan berdasarkan metode Kolmogorov-Smirnov mensyaratkan kurva normal apabila nilai Asymp. Sig. berada di atas batas maximum error, yaitu 0,05. Adapun dalam analisis regresi, yang diuji kenormalan adalah residual atau variabel gangguan yang bersifat stokastik acak, maka data di atas dapat digunakan karena variabel residu berdistribusi normal.

\section{Uji Multikolinearitas}

Multikolinieritas merupakan sesuatu dimana beberapa atau semua variabel bebas berkorelasi tinggi. Untuk mendeteksi ada tidaknya multikolinearitas adalah dengan menggunakan Variance Inflation Factors
(VIF). Dengan bantuan software SPSS 23 diperoleh hasil sebagai berikut :

Dari output di atas dapat dilihat bahwa nilai VIF kurang dari 10 dan nilai Tolarance lebih besar dari 0,100, sehingga dapat disimpulkan bahwa tidak terdapat multikolinearitas dalam data.

\section{Uji Heteroskedastisitas}

\section{Correlations}

\begin{tabular}{|c|c|c|c|}
\hline & & & $\begin{array}{c}\text { Unstan } \\
\text { dardize } \\
\text { d } \\
\text { Residu } \\
\text { al }\end{array}$ \\
\hline \multirow[t]{4}{*}{$\begin{array}{l}\text { Spear } \\
\text { man's } \\
\text { rho }\end{array}$} & $\begin{array}{l}\text { Visibili } \\
\text { ty (X1) }\end{array}$ & $\begin{array}{l}\text { Correlation } \\
\text { Coefficient } \\
\text { Sig. (2- } \\
\text { tailed) } \\
\text { N }\end{array}$ & $\begin{array}{r}-.004 \\
.970 \\
100\end{array}$ \\
\hline & $\begin{array}{l}\text { Credibi } \\
\text { lity } \\
\text { (X2) }\end{array}$ & $\begin{array}{l}\text { Correlation } \\
\text { Coefficient } \\
\text { Sig. (2- } \\
\text { tailed) } \\
\text { N }\end{array}$ & $\begin{array}{r}-.056 \\
.581 \\
100\end{array}$ \\
\hline & $\begin{array}{l}\text { Attract } \\
\text { ion } \\
\text { (X3) }\end{array}$ & $\begin{array}{l}\text { Correlation } \\
\text { Coefficient } \\
\text { Sig. (2- } \\
\text { tailed) } \\
\text { N }\end{array}$ & $\begin{array}{l}.047 \\
.643 \\
100\end{array}$ \\
\hline & $\begin{array}{l}\text { Power } \\
\text { (X4) }\end{array}$ & $\begin{array}{l}\text { Correlation } \\
\text { Coefficient } \\
\text { Sig. (2- } \\
\text { tailed) } \\
\mathrm{N}\end{array}$ & $\begin{array}{r}-.096 \\
.341 \\
100\end{array}$ \\
\hline
\end{tabular}




\begin{tabular}{|l|l|l|l|l|}
\hline \multirow{2}{*}{$\begin{array}{l}\text { Vari } \\
\text { abel }\end{array}$} & $\begin{array}{l}\text { Standar } \\
\text { dized } \\
\text { Coeffici } \\
\text { ents }\end{array}$ & $\begin{array}{c}\text { Correla } \\
\text { tions }\end{array}$ & $\begin{array}{c}\text { Besar } \\
\text { nya } \\
\text { Peng } \\
\text { aruh } \\
\text { Secar } \\
\text { a }\end{array}$ & $\begin{array}{c}\text { Besar } \\
\text { nya } \\
\text { Peng } \\
\text { aruh } \\
\text { Secar } \\
\text { a } \\
\text { Parsi } \\
\text { Zarsi } \\
\text { arder } \\
\text { or } \\
(\mathbf{\%})\end{array}$ \\
\hline $\mathrm{X}_{1}$ & 0.263 & 0.302 & 0.079 & $7.9 \%$ \\
\hline $\mathrm{X}_{2}$ & 0.302 & 0.396 & 0.120 & $12.0 \%$ \\
\hline $\mathrm{X}_{3}$ & 0.363 & 0.420 & 0.152 & $15.2 \%$ \\
\hline $\mathrm{X}_{4}$ & 0.345 & 0.491 & 0.169 & $16.9 \%$ \\
\hline \multicolumn{2}{|l}{ Pengaruh Total } \\
\end{tabular}

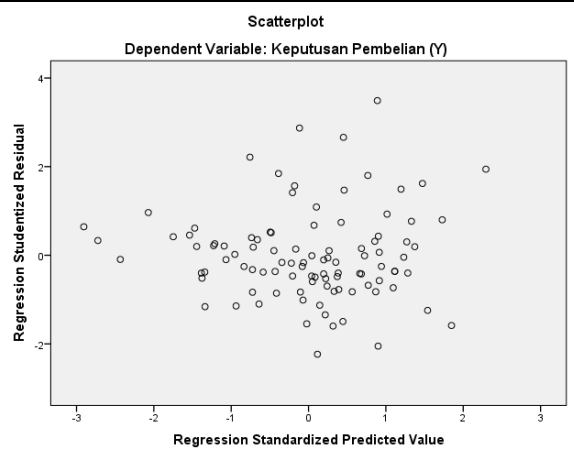

\section{Uji Heteroskedastisitas}

Dari output di atas dapat dilihat bahwa terdapat korelasi yang tidak signifikan. Hal ini dilihat dari nilai p-value (Sig) yang lebih besar dari 0,05. Sehingga dapat disimpulkan tidak terjadi heteroskedastisitas pada model regresi.

\section{Analisis Korelasi Berganda}

Untuk mengetahui hubungan secara bersama-sama antara Visibility $\left(\mathrm{X}_{1}\right)$,
Credibility $\left(\mathrm{X}_{2}\right)$, Attraction $\left(\mathrm{X}_{3}\right)$ dan Power $\left(\mathrm{X}_{4}\right)$ terhadap Keputusan Pembelian (Y), digunakan analisis korelasi berganda (R).

\section{Analisis Korelasi Berganda} Model Summaryb

\begin{tabular}{|l|c|c|c|c|}
\hline $\begin{array}{l}\text { Mo } \\
\text { del }\end{array}$ & $\mathrm{R}$ & $\begin{array}{c}\text { Rquar } \\
\mathrm{e}\end{array}$ & $\begin{array}{c}\text { Adjusted } \\
\text { R Square }\end{array}$ & $\begin{array}{c}\text { Std. } \\
\text { Error } \\
\text { of the } \\
\text { Estima } \\
\text { te }\end{array}$ \\
\hline 1 & $\begin{array}{r}.72 \\
2^{\mathrm{a}}\end{array}$ & .521 & .501 & .18523 \\
\hline
\end{tabular}

a. Predictors: (Constant), Power (X4), Attraction (X3), Visibility (X1), Credibility (X2)

b. Dependent Variable: Keputusan Pembelian (Y)

Berdasarkan hasil output software SPSS di atas, diperoleh nilai koefisien korelasi (R) sebesar 0,722. Hal ini menunjukkan bahwa terdapat hubungan yang kuat antara Visibility $\left(\mathrm{X}_{1}\right)$, Credibility $\left(\mathrm{X}_{2}\right)$, Attraction $\left(\mathrm{X}_{3}\right)$ dan Power $\left(\mathrm{X}_{4}\right)$ terhadap Keputusan Pembelian (Y).

\section{Analisis Pengaruh Parsial \\ Besarnya Pengaruh Secara Parsial}

Pengaruh parsial diperoleh dengan mengalikan standardized coefficient beta dengan zero-order. Berdasarkan tabel di atas, dapat dilihat bahwa besarnya pengaruh $\left(\mathrm{X}_{1}\right)$ terhadap (Y) secara parsial adalah sebesar 7,9\%, besarnya pengaruh $\left(\mathrm{X}_{2}\right)$ terhadap (Y) secara parsial adalah sebesar $12,0 \%$, besarnya pengaruh $\left(\mathrm{X}_{3}\right)$ terhadap (Y) secara parsial adalah sebesar 15,2\%, besarnya pengaruh $\left(\mathrm{X}_{4}\right)$ terhadap $(\mathrm{Y})$ secara parsial adalah sebesar $16,9 \%$. Jadi, total keseluruhan pengaruh Visibility $\left(\mathrm{X}_{1}\right)$, Credibility $\left(\mathrm{X}_{2}\right)$, Attraction $\left(\mathrm{X}_{3}\right)$ dan Power 
(X)terhadap Keputusan Pembelian (Y) secara bersama-sama adalah sebesar $52,1 \%$.

\section{Koefisien Determinasi}

Besarnya pengaruh Visibility $\left(\mathrm{X}_{1}\right)$, Credibility $\left(\mathrm{X}_{2}\right)$, Attraction $\left(\mathrm{X}_{3}\right)$ dan Power $\left(\mathrm{X}_{4}\right)$ terhadap Keputusan Pembelian (Y)dapat ditunjukkan oleh koefisien determinasi dengan rumus sebagai berikut :

$$
\begin{aligned}
\mathrm{KD} & =\mathrm{R}^{2} \times 100 \% \\
& =(0,722)^{2} \times 100 \% \\
& =52,1 \%
\end{aligned}
$$

Artinya variabel Visibility $\left(\mathrm{X}_{1}\right)$, Credibility $\left(\mathrm{X}_{2}\right)$, Attraction $\left(\mathrm{X}_{3}\right)$ dan Power $\left(\mathrm{X}_{4}\right)$ memberikan pengaruh sebesar 52,1\%terhadap Keputusan Pembelian (Y).Sedangkan sisanya sebesar $47,9 \%$ merupakan kontribusi variabel lain selain Visibility $\left(\mathrm{X}_{1}\right)$, Credibility $\left(\mathrm{X}_{2}\right)$, Attraction $\left(\mathrm{X}_{3}\right)$ dan Power $\left(\mathrm{X}_{4}\right)$.

\section{Pengujian Hipotesis Secara Overall ( Uji F )}

Untuk mengetahui signifikan atau tidaknya suatu pengaruh dari variabelvariabel bebas secara bersama-sama atas suatu variabel tidak bebas digunakan uji F.

$\mathrm{H}_{0}$ : Tidak ada pengaruh yang signifikan dari Visibility $\left(\mathrm{X}_{1}\right)$, Credibility $\left(\mathrm{X}_{2}\right)$, Attraction $\left(\mathrm{X}_{3}\right)$ dan Power $\left(\mathrm{X}_{4}\right)$ terhadap Keputusan Pembelian (Y).

$\mathrm{H}_{1}$ : Ada pengaruh yang signifikan dari Visibility $\left(\mathrm{X}_{1}\right), \quad$ Credibility $\left(\mathrm{X}_{2}\right)$, Attraction $\left(\mathrm{X}_{3}\right)$ dan Power $\left(\mathrm{X}_{4}\right)$ terhadap Keputusan Pembelian (Y).

Kriteria Uji : 1. Terima Ho jika $\mathrm{F}$ hitung $<\mathrm{F}$ tabel

2. Tolak Ho jika $F$ hitung $\geq F$ tabel

$\mathrm{F}$ tabel $=\mathrm{F}_{\alpha ;(\mathrm{df} 1, \mathrm{df} 2)} ; \mathrm{df} 1=\mathrm{k}, \mathrm{df} 2=\mathrm{n}-\mathrm{k}-1$
Hasil uji $\mathrm{F}$ berdasarkan pengolahan SPSS disajikan pada tabel berikut :

\begin{tabular}{|l|r|r|r|r|r|}
\hline $\begin{array}{l}\text { Mod } \\
\text { el }\end{array}$ & $\begin{array}{c}\text { Sum of } \\
\text { Squares }\end{array}$ & $\begin{array}{r}\text { Mean } \\
\text { df }\end{array}$ & Square & F & Sig. \\
\hline $\begin{array}{l}\text { Reg } \\
\text { ressi } \\
\text { on }\end{array}$ & 3.547 & 4 & .887 & 25.846 & $\begin{array}{r}.00 \\
0^{\mathrm{b}}\end{array}$ \\
$\begin{array}{l}\text { Resi } \\
\text { dual } \\
\text { Tota } \\
\text { l }\end{array}$ & 3.260 & 95 & .034 & & \\
\hline
\end{tabular}

a. Dependent Variable: Keputusan

Pembelian (Y)

b. Predictors: (Constant), Power (X4), Attraction (X3), Visibility (X1), Credibility (X2)

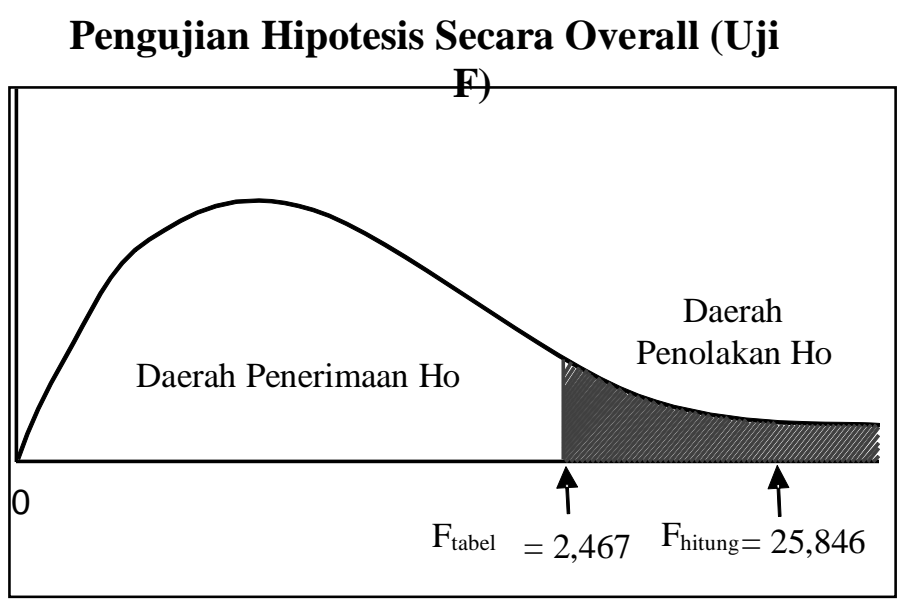

\section{Daerah Penolakan $H_{0}$ Pada Pengujian Secara Bersama-sama}

Dari tabel diatas, diperoleh nilai $\mathrm{F}$ hitung sebesar 25,846. Karena nilai $F$ hitung $(25,846)>\mathrm{F}$ tabel $(2,467)$ dan nilai probabilitas $(0,000<0,005)$, maka Ho ditolak. Dengan demikian dapat disimpulkan bahwa secara simultan terdapat pengaruh 
yang signifikan dari Visibility $\left(\mathrm{X}_{1}\right)$, Credibility $\left(\mathrm{X}_{2}\right)$, Attraction $\left(\mathrm{X}_{3}\right)$ dan Power $\left(\mathrm{X}_{4}\right)$ terhadap Keputusan Pembelian (Y).

\section{Pengujian Hipotesis Secara Parsial ( Uji t ) \\ Untuk mengetahui signifikan atau tidaknya suatu pengaruh dari variabel- variabel bebas secara parsial atas suatu variabel tidak bebas digunakan uji t.} Hipotesis :

- $\mathrm{H}_{01}: \beta_{1}=0$

Visibility $\left(\mathrm{X}_{1}\right)$ tidak berpengaruh signifikan terhadap Keputusan Pembelian (Y).

$\mathrm{H}_{11}: \beta_{1} \neq 0 \quad \begin{aligned} & \text { Visibility } \\ & \text { berpengaruh }\end{aligned} \quad\left(\mathrm{X}_{1}\right)$
signifikan terhadap Keputusan Pembelian (Y).

- $\mathrm{H}_{02}: \beta_{2}=0 \quad$ Credibility $\left(\mathrm{X}_{2}\right)$ tidak berpengaruh signifikan terhadap Keputusan Pembelian (Y).

$$
\mathrm{H}_{12}: \beta_{2} \neq 0
$$

Credibility

$\left(\mathrm{X}_{2}\right)$ berpengaruh signifikan terhadap Keputusan Pembelian (Y).

- $\mathrm{H}_{03}: \beta_{3}=0$

Attraction $\left(\mathrm{X}_{3}\right)$ tidak berpengaruh signifikan terhadap Keputusan Pembelian (Y).

$\begin{aligned} & \mathrm{H}_{13}: \beta_{3} \neq 0 \quad \text { Attraction } \quad\left(\mathrm{X}_{3}\right) \\ & \\ & \text { berpengaruh } \\ & \text { signifikan terhadap } \\ & \text { Keputusan Pembelian } \\ &(\mathrm{Y}) .\end{aligned}$

- $\mathrm{H}_{04}: \beta_{4}=0$ Power $\left(\mathrm{X}_{4}\right)$ tidak berpengaruh signifikan terhadap Keputusan Pembelian (Y).

$\mathrm{H}_{14}: \beta_{4} \neq 0$

Power $\left(\mathrm{X}_{4}\right)$ berpengaruh signifikan terhadap Keputusan Pembelian (Y).

\section{Pengujian Hipotesis Secara Parsial (Uji t)}

\section{Analisis Regresi Berganda}

Untuk melihat pengaruhVisibility $\left(X_{1}\right)$, Credibility $\left(X_{2}\right)$, Attraction $\left(X_{3}\right)$ dan Power $\left(\mathrm{X}_{4}\right)$ Terhadap Keputusan Pembelian (Y) digunakan analisis regresi linier berganda dengan persamaan sebagai berikut

$$
Y=a+b_{1} X_{1}+b_{2} X_{2}+b_{3} X_{3}+b_{4} X_{4}
$$

Analisis Regresi Berganda 


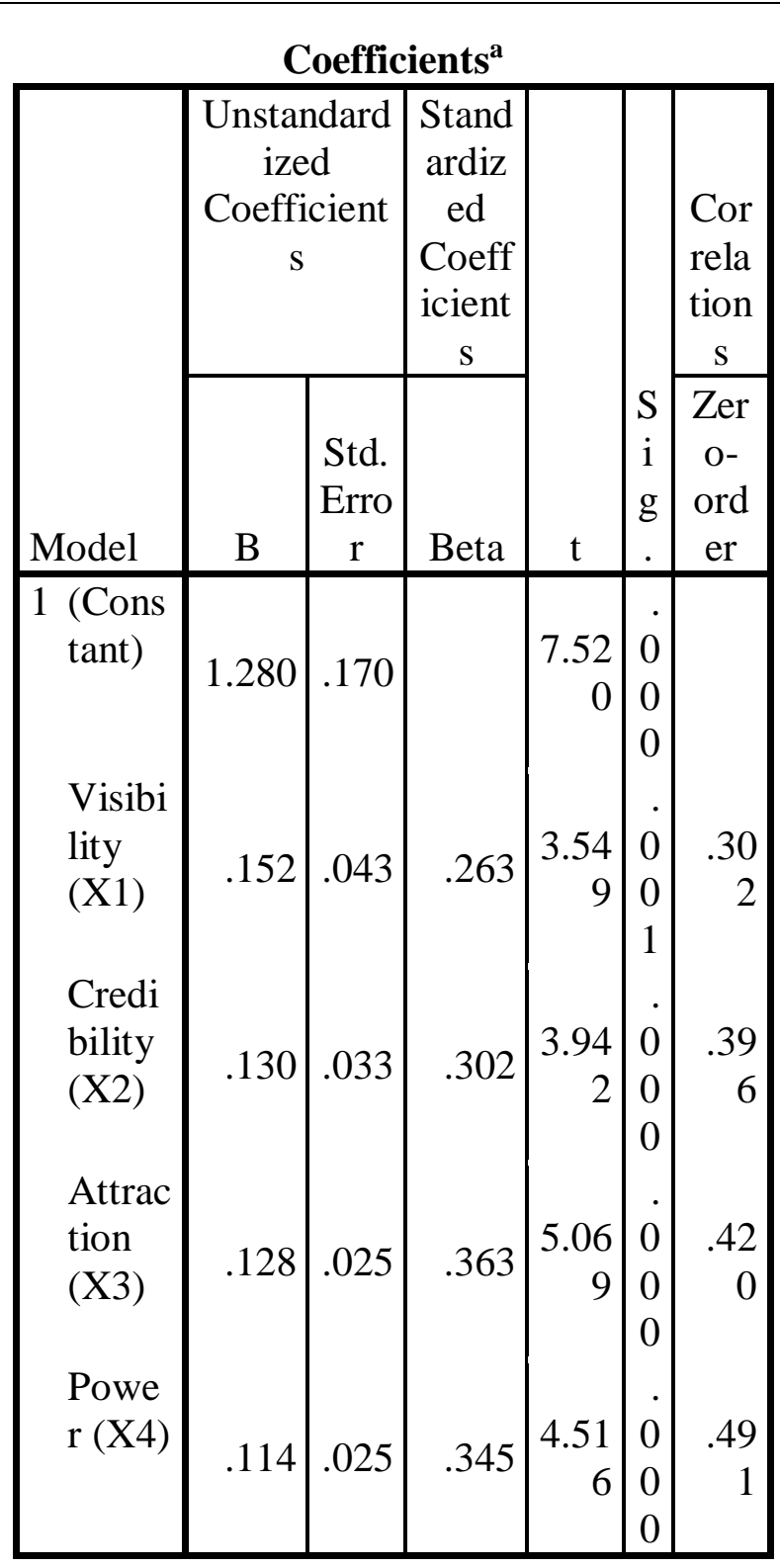

a. Dependent Variable: Keputusan Pembelian (Y)

Berdasarkan hasil perhitungan pada tabel di atas, diperoleh bentuk persamaan regresi linier berganda sebagai berikut : $Y=1,280+0,152 X_{1}+0,130 X_{2}+0,128 X_{3}+$ $\mathbf{0 , 1 1 4} \mathrm{X}_{4}$

Nilai koefisien regresi pada variabelvariabel bebasnya menggambarkan apabila diperkirakan variabel bebasnya naik sebesar satu unit dan nilai variabel bebas lainnya diperkirakan konstan atau sama dengan nol, maka nilai variabel terikat diperkirakan bisa naik atau bisa turun sesuai dengan tanda koefisien regresi variabel bebasnya.

Dari persamaan regresi linier berganda diatas diperoleh nilai konstanta sebesar 1,280. Artinya, jika variabel Keputusan Pembelian (Y) tidak dipengaruhi oleh keempat variabel bebasnya yaitu Visibility $\left(\mathrm{X}_{1}\right)$, Credibility $\left(\mathrm{X}_{2}\right)$, Attraction $\left(\mathrm{X}_{3}\right)$ dan Power $\left(\mathrm{X}_{4}\right)$ bernilai nol, maka besarnya rata-rata Keputusan Pembelianakan bernilai 1,280.

Tanda koefisien regresi variabel bebas menunjukkan arah hubungan dari variabel yang bersangkutan dengan Brand image. Koefisien regresi untuk variabel bebas $\mathrm{X}_{1}$ bernilai positif, menunjukkan adanya hubungan yang searah antara Visibility $\left(\mathrm{X}_{1}\right)$ dengan Keputusan Pembelian (Y). Koefisien regresi variabel $\mathrm{X}_{1}$ sebesar 0,152 mengandung arti untuk setiap pertambahan Visibility $\left(\mathrm{X}_{1}\right)$ sebesar satu satuan akan menyebabkan meningkatnya Keputusan Pembelian (Y) sebesar 0,152.

Koefisien regresi untuk variabel bebas $\mathrm{X}_{2}$ bernilai positif, menunjukkan adanya hubungan yang searah antara Credibility $\left(\mathrm{X}_{2}\right)$ dengan Keputusan Pembelian (Y). Koefisien regresi variabel $\mathrm{X}_{2}$ sebesar 0,130 mengandung arti untuk setiap pertambahan Credibility $\left(\mathrm{X}_{2}\right)$ sebesar satu satuan akan menyebabkan meningkatnya Keputusan Pembelian (Y) sebesar 0,130.

Koefisien regresi untuk variabel bebas $\mathrm{X}_{3}$ bernilai positif, menunjukkan adanya hubungan yang searah antara Attraction $\left(\mathrm{X}_{3}\right)$ dengan Keputusan Pembelian (Y). Koefisien regresi variabel $\mathrm{X}_{3}$ sebesar 0,128 mengandung arti untuk setiap pertambahan Attraction $\left(\mathrm{X}_{3}\right)$ sebesar satu 
satuan akan menyebabkan meningkatnya Keputusan Pembelian (Y) sebesar 0,128. Koefisien regresi untuk variabel bebas $\mathrm{X}_{4}$ bernilai positif, menunjukkan adanya hubungan yang searah antara Power $\left(\mathrm{X}_{4}\right)$ dengan Keputusan Pembelian (Y). Koefisien regresi variabel $\mathrm{X}_{4}$ sebesar 0,114 mengandung arti untuk setiap pertambahan Power $\left(\mathrm{X}_{4}\right)$ sebesar satu satuan akan menyebabkan meningkatnya Keputusan Pembelian (Y) sebesar 0,114.

\section{KESIMPULAN}

1. Pengaruh Visibility terhadap Keputusan Pembelian produk online shop Mayoutfit secara parsial sebesar $7,9 \%$ yang berarti bahwa kepopularitasan Hamidah Rachmayanti terhadap proses keputusan pembelian produk

2. Pengaruh Credibility terhadap Keputusan Pembelian produk online shop Mayoutfit secara parsial sebesar $12,0 \%$ yang berarti bahwa kredibilitas yang dimiliki oleh Hamidah Rachmayanti terhadap proses keputusan pembelian produk Mayoutfit dapat dikatakan baik jika di kategorikan dengan garis kontinum.

3. Pengaruh Attraction terhadap Keputusan Pembelian produk online shop Mayoutfit secara parsial sebesar $15.2 \%$ yang berarti bahwa daya tarik yang dimiliki oleh Hamidah Rachmayanti terhadap proses keputusan pembelian produk Mayoutfit dapat dikatakan baik jika di kategorikan dengan garis kontinum.

4. Pengaruh Power terhadap Keputusan Pembelian produk online shop Mayoutfit secara parsial sebesar
$16,9 \%$ yang berarti bahwa kekuatan dalam mempersuasi yang dimiliki oleh Hamidah Rachmayanti terhadap proses keputusan pembelian produk Mayoutfit dapat dikatakan baik jika di kategorikan dengan garis kontinum.

5. Pengaruh Celebrity Endorser terhadap Keputusan Pembelian secara keseluruhan atau simultan sebesar 52,1\%. Artinya variabel Visibility $\left(\mathrm{X}_{1}\right)$, Credibility $\left(\mathrm{X}_{2}\right)$, Attraction $\left(\mathrm{X}_{3}\right)$ dan Power $\left(\mathrm{X}_{4}\right)$ memberikan pengaruh sebesar 52,1\%terhadap Keputusan Pembelian (Y).Sedangkan sisanya sebesar 47,9\% merupakan kontribusi variabel lain selain Visibility $\left(\mathrm{X}_{1}\right)$, Credibility $\left(\mathrm{X}_{2}\right)$, Attraction $\left(\mathrm{X}_{3}\right)$ dan Power $\left(\mathrm{X}_{4}\right)$ yang tidak diteliti dalam penelitian ini.

\section{DAFTAR PUSTAKA}

A, Shimp,Terence (2003). Periklanan Promosi \& Aspek Tambahan Komunikasi Pemasaran.Terpadu, Jilid II ( edisi 5), Jakarta: Erlangga

A,Shimp Terence (2003). Periklanan Promosi \& Aspek Tambahan Komunikasi Pemasaran.Terpadu, Jilid I ( edisi 5), Jakarta: Erlangga

Abdurrahman, Herdiana Nana. (2015). Manajemen Strategi Pemasaran. Bandung: Pustaka Setia.

J, Setiadi Nugroho. (2008). Perilaku Konsumen: Konsep dan Implikasi untuk Strategi dan Penelitian Pemasaran. Jakarta: Kencana. 
Kotler, Philip and Keller, Kevin Lane. (2013). Manajemen Pemasaran, Jilid 1, Edisi 13. Jakarta: Erlangga.

Kotler, Philip, and Keller, Kevin Lane.(2013). Manajemen Pemasaran, Jilid 2, Edisi 13. Jakarta: Erlangga.

Kotler, Amstrong. (2010). Principles Of Marketing, Global Edition, 13 Edition, New Jersey. Upper Saddle River: Pearson Prentice Hall.

Morissan. (2010). Periklanan: Komunikasi Pemasaran Terpadu, Edisi Pertama. Jakarta: Kencana.

Noor, Juliansyah. (2011). Metodologi Penelitian: Skripsi, Tesis, Disertasi, dan Karya Ilmiah. Jakarta: Kencana.

Priyatno, Duwi. 2014. SPSS 22 Pengolah Data Terpraktis. Andi. Yogyakarta.

Sugiyono. (2011). Metode Penelitian Kombinasi (Mixed Methods). Bandung: Alfabeta.

Sugiyono. (2012). Metode Penelitian Kuantitatif, Kualitatif, dan R\&D. Bandung: Alfabeta.

Suharsaputra, Uhar. (2012). Metode Penelitian: Kuantitatif, Kualitatif dan Tindakan. Bandung: Refika Aditama. 